Marcelo Paixão

Instituto de Economia, Universidade Federal do Rio de Janeiro, Rio de Janeiro, Brasil. mpaixao@ie.ufrj.br

\section{Fernanda Lopes}

Núcleo de Estudos para a Prevenção da AIDS, Universidade de São Paulo/ Comitê Técnico de Saúde da População Negra, Ministério da Saúde, São Paulo, Brasil. lopesf@usp.br
Incidência da AIDS nos contingentes populacionais: existem clivagens?

Fry et al. tratam da "racialização" dos estudos sobre a epidemia de AIDS e das ações governamentais para o seu controle e prevenção.

Seus argumentos podem ser dispostos em dois níveis: (i) da complexidade do sistema classificatório de raça/cor no Brasil e o estudo dos padrões de morbimortalidade desagregado por aquela variável; (ii) da baixa qualidade da base de dados do SINAN-AIDS, que impediria qualquer tentativa de "racialização" do debate sobre a expansão da epidemia de AIDS no Brasil.

Quanto ao sistema de classificação por raça/ cor, o argumento destaca as discrepâncias entre a auto e a hetero-identificação. De fato, na área da saúde, a maioria dos estudos, por razões metodológicas, utilizam-se de indicadores derivados de fontes diferentes.

Se, por um lado, os autores ponderam sobre a validade e consistência das informações, por outro, destacamos: (i) a possibilidade de os estudos sobre desfechos em saúde serem delineados sem que distintas bases de dados sejam cruzadas; e (ii) a necessidade de definição de um padrão único de coleta de dados e de classificação (categorias e denominações). Reconhecemos, sim, a existência do problema, mas não corroboramos a idéia de que ele possa ser utilizado, no plano científico, para invalidar as pesquisas, apenas pelo fato de utilizarem bases de dados distintas.

Os autores questionam a validade da soma de pretos e pardos na categoria negros. Sobre esse questionamento, afirmamos que o procedimento metodológico de junção de pretos e pardos não se restringe à área da saúde, ou da AIDS em especial, esta colocado em diversos campos, há pelo menos duas décadas, como descrito por Silva 1, Guimarães 2 e Barros et al. ${ }^{3}$. No entanto, por ironia, estudos recentes indicam que realmente há fortes motivos para que pretos e pardos sejam analisados de forma desagregada, devido a nem sempre convergência verificada entre os padrões de morbimortalidade 4,5,6, alguns tratados adiante.

Acerca da fragilidade dos indicadores sociais que mostram avanço da epidemia de AIDS na população negra brasileira, em parte concordamos com os autores. No que tange à desagregação dos dados pela variável raça/cor, observamos que, além de a base disponível cobrir um período de tempo relativamente curto (2000/2005), o número relativo de agravos notificados com raça/cor ignorada é sumamente significativo. Por último, há questões relacionadas à subnotificação. Embora não mencionado pelos autores, esse fato apresenta evidente potencial de comprometimento da qualidade daquela (e de outras) base de dados.

O SINAN-AIDS apresenta ainda outros limites, talvez imperceptíveis a Fry et al. Assim, ao analisar a condição sócio-econômica dos casos notificados, utilizando como proxy o grau de escolaridade dos sujeitos, os autores parecem acreditar que a base de dados é robusta o suficiente para contradizer os dados sobre o crescimento e recrudescimento da epidemia nas populações de maior vulnerabilidade social e programática, incluindo os mais pobres. Os autores chegam a várias conclusões sem maiores questionamentos: será que não haveria discrepâncias entre a informação sócio-econômica fornecida pela pessoa infectada e o seu real nível de escolaridade, o que ampliaria a chance de as pessoas com maior escolaridade serem corretamente identificadas pelos trabalhadores da saúde? Será que a política nacional de AIDS não estaria se apresentando mais efetiva para aqueles que detêm melhor padrão de vida (majoritariamente brancos) vis-à-vis aos mais pobres (primordialmente negros), exigindo por parte do poder público especial esforço para alertar este segmento populacional sobre as vias de infecção, sinais e sintomas, recursos preventivos ou tratamento? Ou será que, para os estudiosos, o problema com a base de dados do SINAN-AIDS ocorre tão-somente quando as informações contradizem suas opiniões?

Alguns estudos podem nos ajudar a elucidar se essa base de dados guarda algum nível de correspondência com a realidade. Pinho et al. 7 observaram que negros e negras sexualmente ativos tinham menos conhecimentos sobre DST-HIV/ AIDS, menor percepção de risco de infecção por HIV, e praticavam menos sexo seguro. Já entre a população jovem sexualmente ativa (16-24 anos) o uso de preservativo era mais freqüente, mas se desagregados os dados por sexo e raça/cor, $42 \%$ das jovens brancas relataram praticar sexo protegido contra $28 \%$ das negras; não se observaram, entre os rapazes, diferenças significativas neste aspecto. Em nota oficial, o Ministério da Saúde destacou que, segundo pesquisa realizada pelo Instituto Brasileiro de Opinião Pública e Estatística (IBOPE), há diferenças quanto ao não-uso do preservativo por falta de recursos financeiros entre a população masculina sexualmente ativa de 14 anos e mais: $45 \%$ dos negros e $37,6 \%$ dos brancos, também as mulheres e os homens negros aparecem como aqueles que detêm menos acesso a informações sobre DST-HIV/AIDS e ao teste anti-HIV. 
Logo, com base nessas informações, não é justo ou coerente afirmar que as investigações sobre incidência da epidemia de AIDS nos diferentes segmentos populacionais (e no seu interior) sejam irrelevantes. Bastos ${ }^{8}$, um dos membros da equipe de Fry, corrobora com a luta antiracista ao afirmar que "É preciso ter em mente que a questão racial não pode ser secundarizada em nosso país, e que ela quase invariavelmente constitui uma dimensão explicativa fundamental dos mais diversos fenômenos sociais, que vai se somar às diferentes heterogeneidades de uma sociedade justa e excludente".

Paixão et al. 6 analisaram a evolução das razões de mortalidade por AIDS para as populações masculina e feminina, segundo raça/cor, no período de 2001 a 2004. Em 2004, as razões de mortalidade de pretos mantinham-se superiores: 19,$03 ; 10,98$ para os brancos; 6,75 para os pardos. Para as mulheres, as razões foram menores que para os homens e semelhantes nos diferentes grupos de cor: pretas, 10,71; brancas, 4,36; e pardas, 3,38. Ao desagregar o indicador por sexo, faixa etária e raça/cor verificou-se que, entre os homens, independentemente da raça/ cor, a faixa modal situava-se entre 26 e 39 anos de idade. Chamou a atenção o fato de que, para os negros, as razões de mortalidade apareciam menores em todos os grupos etários selecionados. Porém, ao se analisar as curvas descritas para pretos e pardos, foram nítidas as diferenças entre esses e entre pretos e brancos. Entre as mulheres, observou-se que as pretas apresentavam razões de mortalidade superiores em relação às pardas e às brancas, independente dos grupos etários selecionados.

Ainda vemos a necessidade de, rapidamente, comentar a afirmação dos autores sobre a existência de eventual tendência de crescimento da epidemia na população parda em detrimento da preta. Embora o grupo utilize dados do SINANAIDS para explicar o evento, asseguramos que, a partir deles, o argumento carece de fundamentos, pois as variações observadas entre 2004 e 2005 foram muito pequenas e sem significância estatística (no total de registros, o porcentual de pardos passou de $25 \%$ para $27 \%$ e o de pretos de $10,7 \%$ para $10,2 \%$ ). Coerentemente, ao analisarmos os dados do SIM, verificamos que, embora as razões de mortalidade por AIDS fossem maiores entre os brancos, as taxas foram sumamente superiores para os pretos, quando comparados aos brancos e aos pardos. Usando como parâmetro os dados do censo de 2000, vemos que os pretos perfaziam um total de $6,2 \%$ do total da população brasileira, os pardos $39 \%$ e os brancos 53\%; no entanto, a participação dos pretos na base de dados do SINAN-AIDS era 4,5\% acima de sua participação relativa na população como um todo, ao passo que, para pardos e brancos, era inferior em, respectivamente, $14 \%$ e $5,2 \%$.

Para além de os indicadores do SIM apresentarem coerência em relação aos do SINAN-AIDS, ao cruzarmos as informações de ambos os sistemas, verificamos que, na medida em que o porcentual de registros de adoecimento ou morte por AIDS com raça/cor ignorada diminuiu, mais relevante foi o peso guardado pelo agravo nos distintos grupos de cor selecionados.

Portanto, podemos afirmar que existem clivagens raciais (ou de cor) no grau e no modo como a AIDS incide na população. Não obstante, é preciso que novos empreendimentos investigativos sejam realizados. Cabe aos gestores considerar que informações como essas devem ser mais bem estudadas, com vistas a orientar o planejamento em saúde nas suas múltiplas dimensões, organizar as ações e, por conseguinte, contribuir no controle, prevenção e tratamento de doenças e agravos. Nesse sentido, a efetividade das decisões depende, fundamentalmente, da capacidade daqueles atores em compreender as diferentes dinâmicas que se apresentam entre e intragrupos, incluindo aquelas balizadas por sexo, idade, raça/cor, condição social e local de residência.

Para Fry et al., na esperança de tão-somente não racializar o debate sobre políticas públicas no Brasil, esses diferenciais deveriam ser mantidos como termos proibidos, tabus; deveriam ser discutidos única e exclusivamente no interior das rodas acadêmicas e/ou grupos de pesquisa. Apesar da gravidade das situações estudadas, as pesquisas que analisam dados desagregados por raça/cor são vistas pelos autores como males em si mesmas, como se o debate acerca das desigualdades raciais e seu impacto nos desfechos de saúde necessariamente implicassem a defesa de perspectivas racialmente supremacistas. Talvez não coincidentemente por esse motivo os autores, após breve análise das informações contidas no SINAN-AIDS, tenham se esmerado para mostrar que as ações do poder público não estavam cientificamente respaldadas e sim orientadas para "formar uma consciência racial".

No plano científico, essa linha de pensamento demonstra, no mínimo, uma tentativa de ocultamento de aspectos sumamente relevantes de nossa realidade social, e contribui para que seja quase insolúvel (e, quiçá, inexorável) o problema das assimetrias raciais. No plano político, difícil mesmo é entender os motivos pelos quais levariam você leitor, ou mesmo nós, a acompanhar esses passos. 
1. Silva NV. O preço da cor: diferenciais raciais na distribuição da renda no Brasil. Pesqui Planej Econ $1980 ; 10: 21-44$

2. Guimarães A. Classes sociais, raças e democracia. São Paulo: Editora 34; 2002.

3. Barros RP, Henriques R, Mendonça R. Desigualdade e pobreza no Brasil: retrato de uma estabilidade inaceitável. Rev Bras Ciênc Soc 2000; 15:12741.

4. Batista LE, Escuder MML, Pereira JCR. A cor da morte: causas de óbito segundo características de raça no Estado de São Paulo, 1999 a 2001. Rev Saúde Pública 2004; 38:630-6.

5. Batista LE, Volochko A, Ferreira CEC, Martins V. Mortalidade da população negra adulta no Brasil. In: Lopes F, organizador. Saúde da população negra no Brasil: contribuições para a promoção da eqüidade. Brasília: Fundação Nacional de Saúde, Ministério da Saúde; 2005. p. 237-314.

6. Paixão M, Carvano LM, Oliveira J, Ervatti L. Contando vencidos. In: Lopes F, organizador. Saúde da população negra no Brasil: contribuições para a promoção da eqüidade. Brasília: Fundação Nacional de Saúde, Ministério da Saúde; 2005. p. 49-190.

7. Pinho MD, Berquó E, Lopes F, Oliveira KA, Lima LCA, Pereira N. Juventudes, raça e vulnerabilidades. Revista Brasileira de Estudos de População 2002; 19:277-94.

8. Bastos FI. Entre a consertação perversa e o varejo político: a complexa trajetória reprodutiva das mulheres negras e pardas. In: Monteiro S, Sansone L, organizadores. Etnicidade na América Latina: um debate sobre raça, saúde e direitos reprodutivos. v. 1. Rio de Janeiro: Editora Fiocruz; 2004. p. 249-56.

\section{Rita Barradas} Barata

Faculdade de Ciências Médicas, Santa Casa de São Paulo, São Paulo, Brasil. rita.barata@fcmscsp.edu.br

\section{A politização dos riscos}

Desde o início da epidemia de AIDS, a politização inerente ao processo, seja pelos preconceitos associados à enfermidade e aos enfermos, seja pela gravidade do problema ou ainda pela possibilidade de vocalização de demandas por parte de alguns grupos afetados ou ameaçados, os dados e informações epidemiológicas foram sempre instrumentos desta politização mais do que referências objetivas para compreender a distribuição populacional da doença. Talvez, nunca antes na história do controle de doenças transmissíveis tal fato tenha ocorrido em tais proporções.

Podemos lembrar da criação de "indicadores" especiais para o programa de AIDS sem nenhuma expressão propriamente epidemiológica, ou seja, sem equivalência como medida de risco, cuja única finalidade era fornecer material para as demandas políticas em torno da doença. $\mathrm{O}$ cálculo de uma "taxa de incidência acumulada", por exemplo, produzia o esperado efeito de $\mathrm{mar}$ keting de sugerir um aumento desenfreado do risco, mas não ajudava a compreender a evolução real da doença. Esse indicador só foi substituído quando passou a ser interessante, politicamente, demonstrar o impacto da terapia anti-retroviral.

Do mesmo modo, alegando a impossibilidade de determinar exatamente a dimensão da população exposta, até hoje a maioria dos programas analisa a distribuição dos casos segundo possíveis modos de transmissão lançando mão de proporções em vez de utilizar taxas. Se fossemos usar o mesmo raciocínio para outros problemas de saúde jamais poderíamos utilizar taxas.

O problema de usar proporções em vez de taxas é que, no mais das vezes, os autores e os leitores se equivocam e tendem a interpretar as proporções como se fossem medidas de risco. Um exemplo óbvio é a idéia bastante difundida de que o risco é maior atualmente para heterossexuais, o que é rigorosamente falso.

Se utilizarmos as estimativas de tamanho dos grupos populacionais de usuários de drogas injetáveis, homossexuais e heterossexuais elaborados para o programa de DST/AIDS e projetarmos estas estimativas para obter os denominadores das taxas, veremos que o risco continua sendo extremamente alto para os usuários de drogas injetáveis (taxa de incidência de 169,2 casos por 100 mil usuários em homens e 161,8 casos por 100 mil usuários em mulheres) e para os homossexuais masculinos (95,3 casos por $100 \mathrm{mil}$ homossexuais) se comparado às taxas de incidência para homens e mulheres heterossexuais (8,0 casos e 10,4 casos por 100 mil, respectivamente). Portanto, ainda que as taxas apresentem tendência declinante a partir da introdução do tratamento, os riscos seguem sendo muito importantes e diferenciados.

A análise das proporções distorce a avaliação sugerindo que o risco é menor entre usuários e homossexuais em decorrência do aumento proporcional do grupo de heterossexuais. Como as proporções não medem risco e sim a composição relativa do total de casos segundo modo de transmissão, o aumento relativo de um grupo resulta inevitavelmente na redução proporcional dos demais sem que isto signifique redução ou aumento do risco.

Do mesmo modo podemos extrapolar esses comentários para os aspectos tratados pelos autores no artigo em debate. Ao analisarmos apenas a distribuição proporcional por escolaridade ou cor da pele, não podemos inferir destes dados nada acerca do risco dos diferentes grupos. Por 